\title{
Applications and Contributions of Physics to the Surface Treatment Process of Materials Part II: Other Treatments
}

\author{
Omar Alvarez, A. Barba, A. Rojas, R. González, R. Valdez, A. Covelo, M. Hernández
}

\begin{abstract}
In this second part another group of processes of surface treatment of materials in which has been employed a series of principles of the Physics are reviewed. Using technologies that employ these principles it is possible to modify the surface of materials in order to obtain improvements in their behavior, especially in regard to increasing their corrosion, wear or fatigue resistance. In particular, this work describes the processes of flame and induction hardening, surface treatments using laser beam, treatments that use concentrated solar energy and finally the processes of physical vapor deposition. All of them of industrial application, with the exception of the use of concentrated solar energy which, however, has an important potential due to the current situation of the renewable energies.
\end{abstract}

Index Terms-Applications of Physics; Surface Treatment of Materials; Use of Concentrated Energy.

\section{INTRODUCTION}

As in many other areas of daily life and industrial work, Physics has also contributed in a decisive way to the development of Surface Treatment of Materials in which a group of processes that improve the performance of the surface area of a material, they also produce a better response to deterioration mechanisms such as corrosion, wear or fatigue. In this second part, other examples of processes are presented and different principles of Physics are pointed out that have contributed to the development of those processes and to improve the behavior of materials in equipment and industrial systems.

\section{Surface TREATMENTS USING VARIOUS FORMS OF ENERGY}

\section{A. Flame Hardening}

Flame hardening, in a similar way to induction hardening, laser hardening and hardening using concentrated solar energy, have as their common objective to achieve a surface hardening through a modification of the microstructure that occurs on the surface of a steel or an iron casting in order to provide them with better wear resistance, retaining an inner section with qualities of adequate toughness [1].

Published on April 30, 2018.

O. Alvarez is with Instituto de Energías Renovables, UNAM. Temixco, Morelos, México. (e-mail: omalb@ier.unam.mx)

A. Barba, R. González, R. Valdez, A. Covelo, and M. Hernández are with Centro de Ingeniería de Superficies y Acabados (CENISA), División de Ingeniería Mecánica e Industrial, Facultad de Ingeniería UNAM, Circuito Exterior, Ciudad Universitaria, México.

A. Rojas is with Departamento de Termofluidos, División de Ingeniería Mecánica e Industrial, Facultad de Ingeniería, UNAM, Edificio del Centro de Ingeniería Avanzada, 3er Piso. C.U. México
The flame hardening uses the combustion of a hydrocarbon such as acetylene, and oxygen to heat for a few seconds the surface of a steel or an iron casting, to bring it to an appropriate temperature to achieve a specific microstructure (austenite), and then quickly cool it in media such as water, oil or a salt-water solution and cause the microstructure to change, especially in the surface area (the name of the microstructure is martensite), which as a consequence, generates an increase of the superficial hardness of the material without substantial change in the central zone of the piece. With the combination of both characteristics (high superficial hardness and high toughness inner section) allows applications in components such as gears, pinions, etc. [2]. Additionally, this transformation produces compression stresses which can act to reduce the risks of crack grow and thus prevent the fracture of an industrial piece. Fig. 1 shows a diagram showing the common components in a flame hardening system [3].

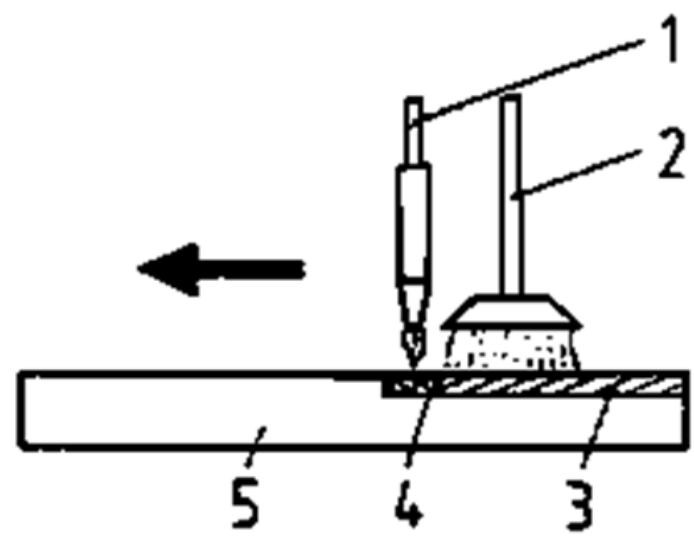

Fig. 1. Schematic of the components of a device to perform flame hardening. 1. Oxygen-acetylene torch. 2 System for rapid cooling (quenching) of the piece heated with the torch 3. Surface area that has been heated by the flame 4 . Zone transformed to martensite after quenching 5.Steel or cast iron subjected to the treatment. [1].

Fig. 2 illustrates a system of several burners that heat a piece for subsequent cooling in the liquid medium that appears in the lower part of the image. The treated area where surface quenching is achieved by this method is often in the order of 1 to $7 \mathrm{~mm}$

In the flame hardening process, the phenomenon of heat transport is fundamental for both the heating and the cooling stages so that the required changes (phase transformations) in the treated materials can be achieved. Some limitations of the process are associated with the complications to achieve an adequate control of the thickness and uniformity of temperatures and characteristics of the treated area [4]. The phenomenon is described in a by Fourier law for heat conduction within the piece, and for heating and cooling in 
the outer surface of the piece, the Newton law for heat convection [23]. The Fourier law in a differential from, states:

$$
\vec{q}=-k \nabla T
$$

Which implies that the heat flux $\vec{q}$ is opposite to the thermal gradient $\nabla T$, and proportional to the thermal conductivity $k$. The Newton law for heat convection states:

$$
\vec{q}=h\left(T_{S}-T_{\infty}\right)
$$

Which implies that heat flux $\vec{q}$ has $h$ proportion to the temperature difference between the surface and the surrounding fluid $\left(T_{S}-T_{\infty}\right)$ (i.e. the flame or the air for each situation). $h$ is often obtained experimentally, and sometimes considering theoretically relations with the phenomena.

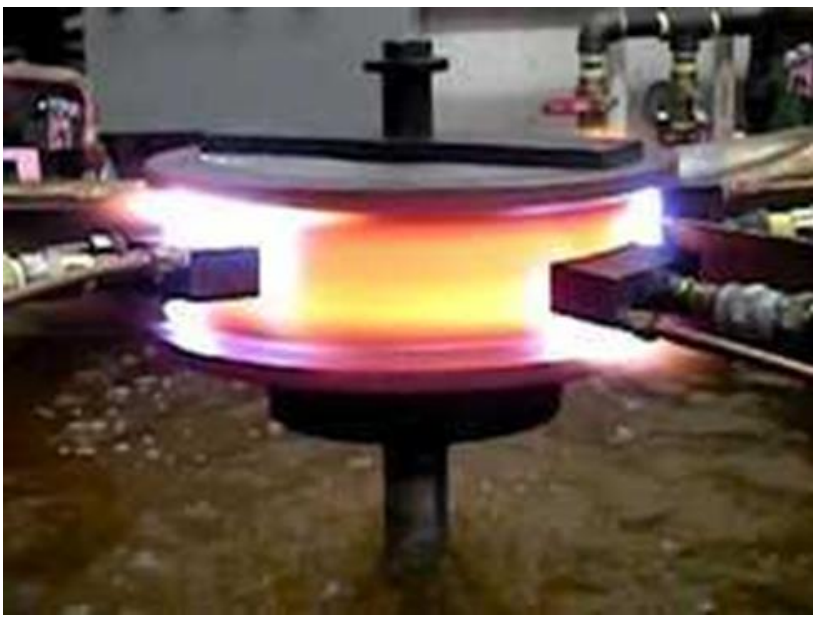

Fig. 2. Image of an industrial flame hardening process, of an industrial piece $^{1}$

\section{B. Induction Hardening}

When an alternating current is applied to the primary coil of a transformer, an electromagnetic field is generated. According to Faraday's Law, if the secondary of the transformer is placed inside the magnetic field, an electromotive force, and then a current is induced. Faraday's law states that electromotive force $\varepsilon$, is produced by the variation on time of the magnetic flux that passes through a closed loop conductor $\frac{d \Phi_{B}}{d t}$ and opposite to it (stated by Lenz law, described by the negative sign)[24]:

$$
\varepsilon=-\frac{d \Phi_{B}}{d t}
$$

Then with this electromotive force, a current will be established in that conductor, originating a Foucault current. The current will finally cause a heating of the conductor as the Joule effect manifests. The equation for Joule effect states:

$$
J=\varepsilon I t
$$

${ }^{1}$ http://www.indiamart.com/metalheattreatersengineers/flame-hardeningservices.html
Which implies that heat $J$ is proportional to the quantity of electricity or charge passed through the conductor It and to the electromotive force $\varepsilon$ [25]. Based on this principles, in a basic configuration of induction heating, a power source generates an alternating current that passes through an inductor (usually a copper coil) and the piece to be heated is placed inside the mentioned inductor. (See Fig. 3). The inductor acts as the primary of the transformer and the piece becomes the secondary circuit. When the metallic piece is crossed by the magnetic field, Foucault currents (also known as Eddy currents) are induced in the piece to be heat treated.

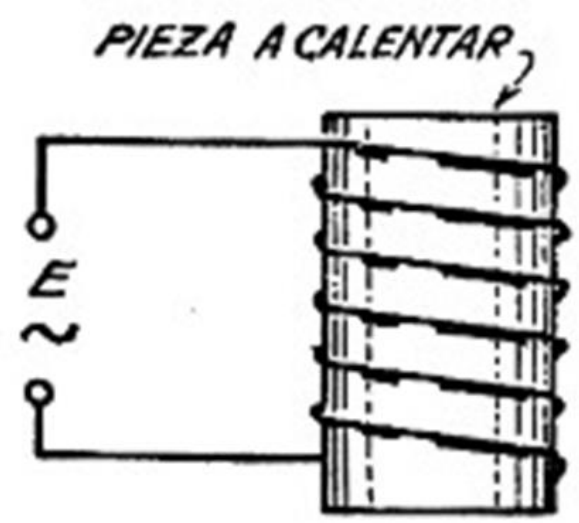

Fig. 3. Schematic of induction heating

As a result of the phenomena described above, a potential difference is generated that gives rise to the circulation of an electric current inside the piece, which causes its heating by Joule effect.

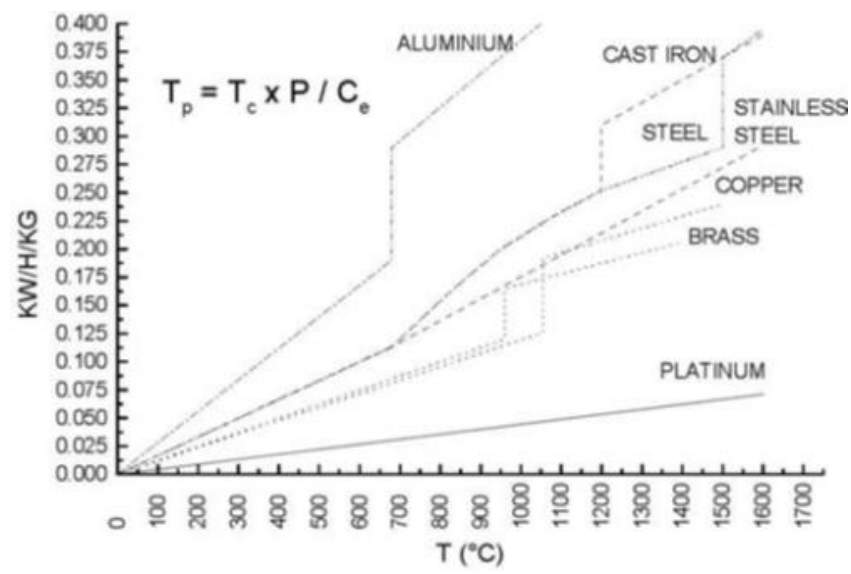

Fig. 4. Ratio of heating power vs temperature reached for different metallic materials [5].

The thickness of the heated layer depends on the frequency of variation of the magnetic field and the characteristics of the material to be hardened, as can be seen in Fig. 4, [5]. Frequencies are used around $1 \mathrm{kHz}$ for hardened layers of great thickness (5-9 $\mathrm{mm})$; and high frequencies around $500 \mathrm{kHz}$, for hard layers of 0.4 to $2 \mathrm{~mm}$ thick. Other control parameters are the intensity of the magnetic field and the duration of the treatment. Once the heating has been carried out, the piece is quenched (as in the case of flame hardening), by immersion or spraying with a suitable liquid.

A more detailed schematic of this process is in Fig. 5, with some of the physical phenomena and features of an 
induction heating system. It can be mentioned among those: the electric current flowing through a copper conductor, Eddy currents, magnetic fields, the high-frequency $\mathrm{AC}$ power, to point out a few.

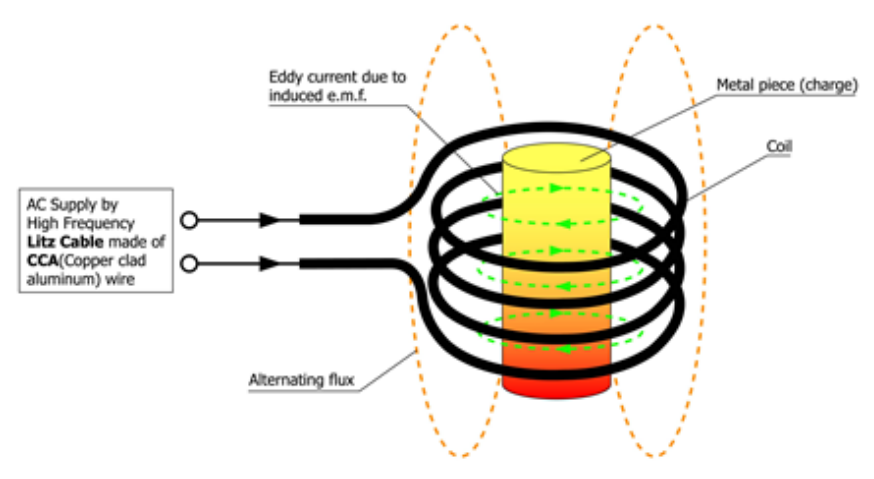

Fig.5. Illustration of some phenomena that occur during induction heating, and the characteristics of the current used and the components of a surface tempering system by induction ${ }^{2}$

On the other hand, in Fig. 6 an image of a piece placed in an induction heating system can be observed with the coils surrounding the sample that will later be cooled for its surface hardening.

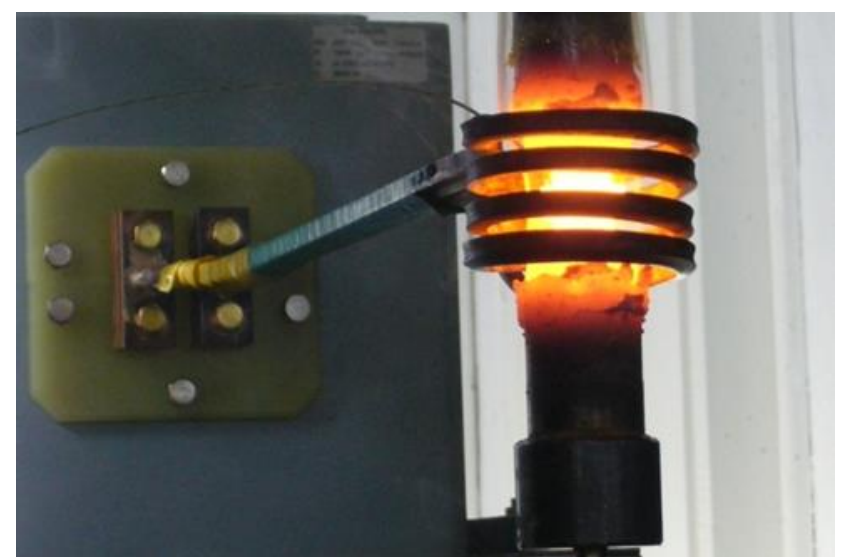

Fig. 6. Image of the induction heating of a piece that is subsequently cooled in an appropriate medium to obtain induction hardening ${ }^{3}$

Similar to what happens with flame hardening, it is applied to parts such as gears, pinions, crankshafts and all those that may require a surface of high hardness and an inner central part of adequate toughness [6],[7]. Recently, the contributions of the modeling and simulation procedures have been added to these treatments with the aim of optimizing these processes [8].

\section{Laser Surface Treatment}

Laser radiation is an electromagnetic radiation of concentrated light, and concentrated with adequate optical systems described in [9],[10], which is in the range of the infrared; and upon impact on a metal surface produces a generation of heat. The action of the laser beam for seconds -or even fractions of a second- allows to heat the surface of the piece to the appropriate temperature while the rest remains at low temperature and without any transformation

${ }^{2} \mathrm{http} / / / \mathrm{hflitzwire.com/faq/}$

${ }^{3}$ http://www.iew.eu/de/Wissenschaft_und_Pr\%C3\%BCftechnik.html/ of the microstructure. The phenomena studied by Physics that allows to increase the thermal energy of the piece is the absorbance if irradiation, that states that a material will have a net influx of energy $G_{a b s}$, in a proportion $\alpha$ of the irradiation that reaches the surface $G$. The value of $\alpha$ is dependent of the irradiation spectrum, as well as the physical conditions of the surface itself (i.e. material, roughness, etc.) [23]:

$$
G_{a b s}=\alpha G
$$

A significant temperature difference is generated between the inner and the surface, due to the very high heating and cooling speeds that can be achieved, which makes it possible steel hardening when the laser beam is no longer applied without the need to introduce the piece in a liquid to cool. With this method hardened layers of 0.20 to $1.5 \mathrm{~mm}$ thick can be achieved. The equipment used requires relatively high investment (but increasingly smaller with time), and does not allow to reach depths greater than $2 \mathrm{~mm}$. The process is very useful for hardening steels with low hardening capacity (hardenability) or areas of a piece difficult to access by other methods, besides being able to achieve surface hardening in much shorter times than those required with other types of treatments such as thermochemical treatments (carburizing, nitriding, etc); also, very good results are capable to be obtained for other alloys such as $\mathrm{Mg}$ alloys, achieving results of hardness and wear resistance even two times greater than non-treated [22]. Additionally, the laser allows this hardening processes to be carried out at high speed, which together with the welldefined working area, achieves a minimum distortion of the pieces. Moreover, this geometrically precise heat treatment with its unneeded liquid cooling allows the process to be greatly accelerated, obtaining excellent results. In Fig. 7 it can be seen a simplified scheme of the action of the laser beam on a piece [11]-[13].

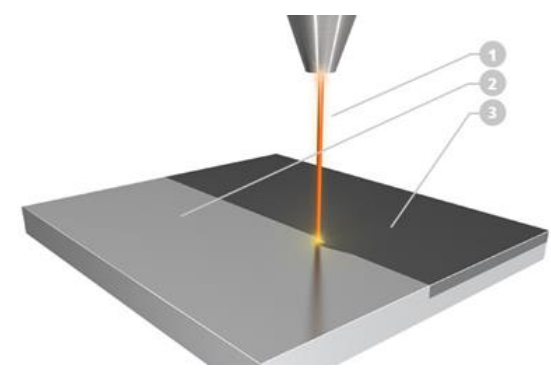

Fig. 7. Schematic of an arrangement of the common components of a laser surface treatment system: (1) laser beam, (2) zone still without treatment and (3) area already treated with laser radiation ${ }^{4}$

It is worth mentioning that using this type of radiation can also be melted various types of powders and its combinations on the surface to obtain coatings at surface, or modify the structure of a coating previously placed by some other technique; and of course with the appropriate type of laser, it is possible to carry out welding and cutting processes of materials. Recently, also sintering processes of metallic and ceramic materials or additive manufacturing technologies are performed (Fig. 8).

${ }^{4}$ https://www.or-laser.com/en/laser-hardening 


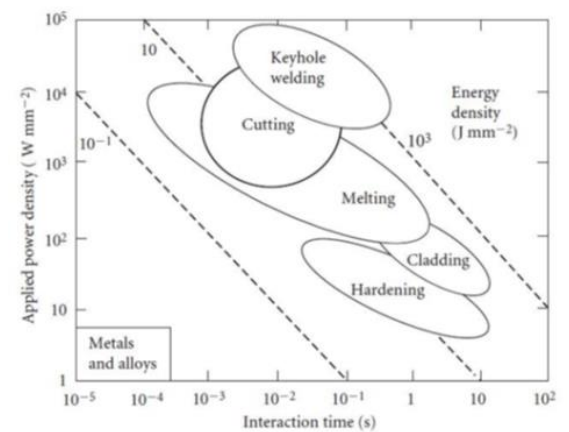

Fig. 8. Diagram showing the relationship between the interaction time and the power of a laser to be used, for desired effects obtained in metals and alloys [12].

In relation to the previously mentioned, in Fig. 8 it can be observed how depending on the power of the laser and the time of interaction with the material, it can only be superficially heated, melt surface material or melt a material provided to coat a substrate, or even cut, weld or drill. As can be seen and expected, higher powers and longer interaction times produce greater effects on the material. An example of the industrial application of laser quenching can be seen in Fig. 9, in which it is indicated how the laser beam impacts the industrial piece. Commonly, the systems for these processes are capable to move the beam, so the entire surface can be reached and achieve a uniform result of the treatment in short time.

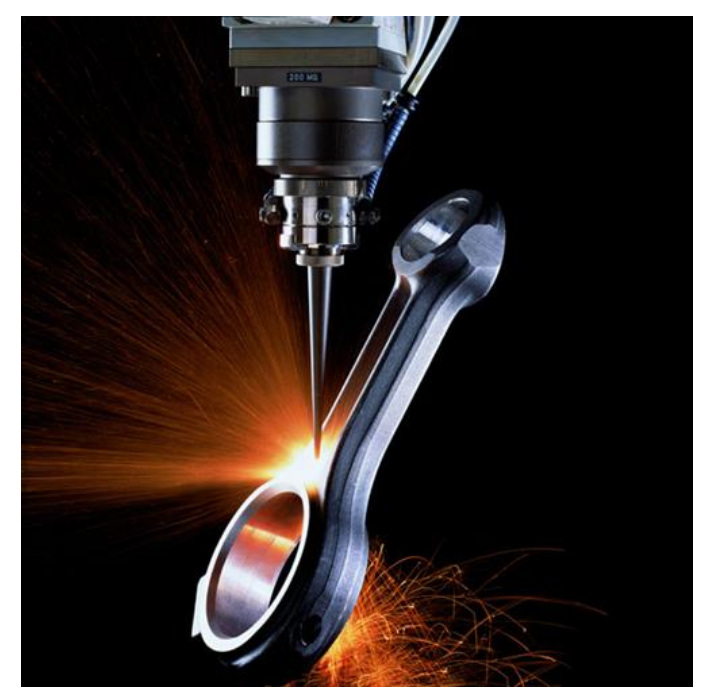

Fig. 9. Image of an industrial piece for mechanical applications (connecting rod), which is heat treated with a laser beam ${ }^{5}$

Fig. 10 shows how heat is distributed and transported during a laser treatment and it can be observed that phenomena can occur by convection, as well as radiation and conduction. It is also shown how the characteristics of the material, have influence for the development of the process, such as absorbance in the laser spectrum; giving a resultant time for the laser to sweep the entire piece. Then it is convenient to highlight in laser systems, the contribution of optics and thermodynamics, as fundamental branches of physics for the achievement of surface treatments through the use of laser radiation.

${ }^{5}$ http://www.deltatherm.com/usage/

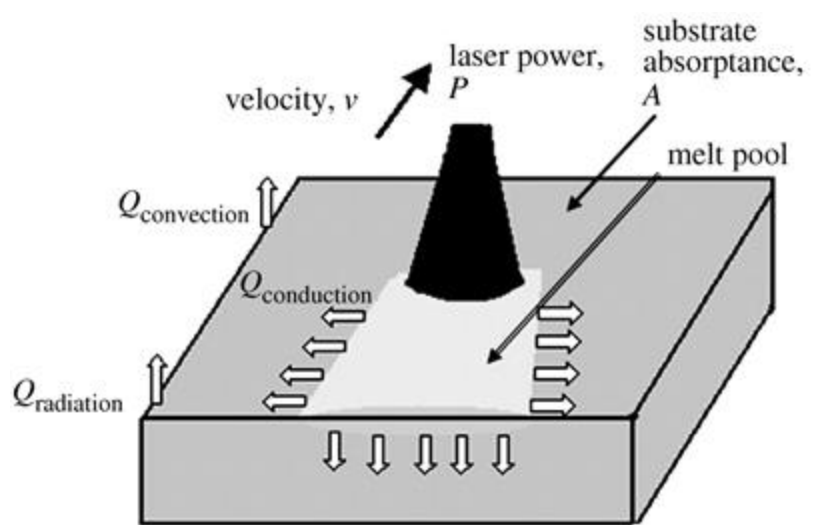

Fig. 10. Diagram showing how combined heat phenomena and dynamics of the piece would occur in a piece treated by a laser process.

\section{Surface treatments using Concentrated Solar Energy (CSE)}

A newer technology, is the use of concentrated solar energy to treat the surface of materials. In the variety of concentration systems, the application of different optical systems with different lenses and mirrors stands out. An example of this is the scheme shown in Fig. 11, which shows the difference between a conventional lens and a Fresnel lens where the irregularities of the Fresnel lens allow a more versatile concentration system [14, [15]. The operation of this kind of concentrators is able due to the refraction phenomena, described by Snell law (some authors attribute this to Thomas Harriot), that states [21]: "The ratio of the sine of the angle of incidence to the sine of the angle of refraction is a constant for media of specific optical densities" in the point of interface.

This can be interpreted as:

$$
\frac{\sin \theta_{1}}{\sin \theta_{2}}=k=\frac{n_{2}}{n_{1}}
$$

Where $\frac{n_{2}}{n_{1}}$ defines the constant $k$, as the ratio of the specific optical densities. Thus, as the direction of light changes its direction when it passes through a different media (i.e. glass), some lenses like convex or Fresnel lens may concentrate solar irradiation, and then the piece will be heated due to effect of the phenomena describe by eq. (5), but by absorbing the solar spectrum. In Fig. 12 it can be seen a prototype of a solar concentrator that uses a Fresnel lens built in the Facultad de Ingeniería, UNAM, México. Also, a new prototype with a larger lens is being built, in which it is expected to be able to achieve also higher temperatures. The first prototype has achieved $500{ }^{\circ} \mathrm{C}$ and the new equipment is expected to reach $1000{ }^{\circ} \mathrm{C}$ for similar receptors. With an equipment similar to these, a whole series of surface treatments and even other types of processes such as welding or sintering of metallic and ceramic materials have been carried out [16],[17]. It is a very attractive field in which a series of works are being developed, and in many of the cases with potential for application in the short and medium term in the industrial sectors, an example of these, are the NiAl coatings on carbon steel substrates obtained by self-propagating high-temperature synthesis, but assisted with concentrated solar energy to ignite the reaction [20]. As the process is also economic, environmental friendly and 
could be carried out even with small concentrators, the process could be easily introduced to industry.

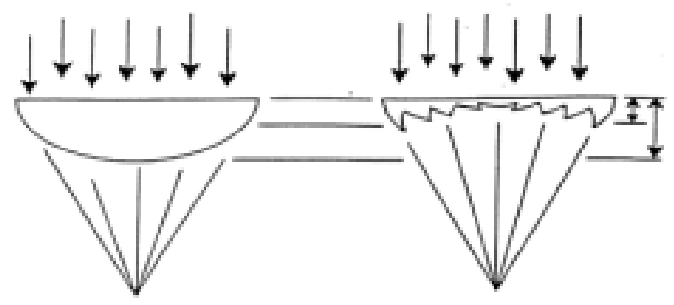

LENTE CONVENCTON.AL

LENTE DEFRESNEL

Fig. 11. Schematic that allows comparing a conventional lens and a Fresnel lens, in which, due to the changes of section shown by the lens itself, it is possible to improve the versatility of the concentration systems for solar irradiation.

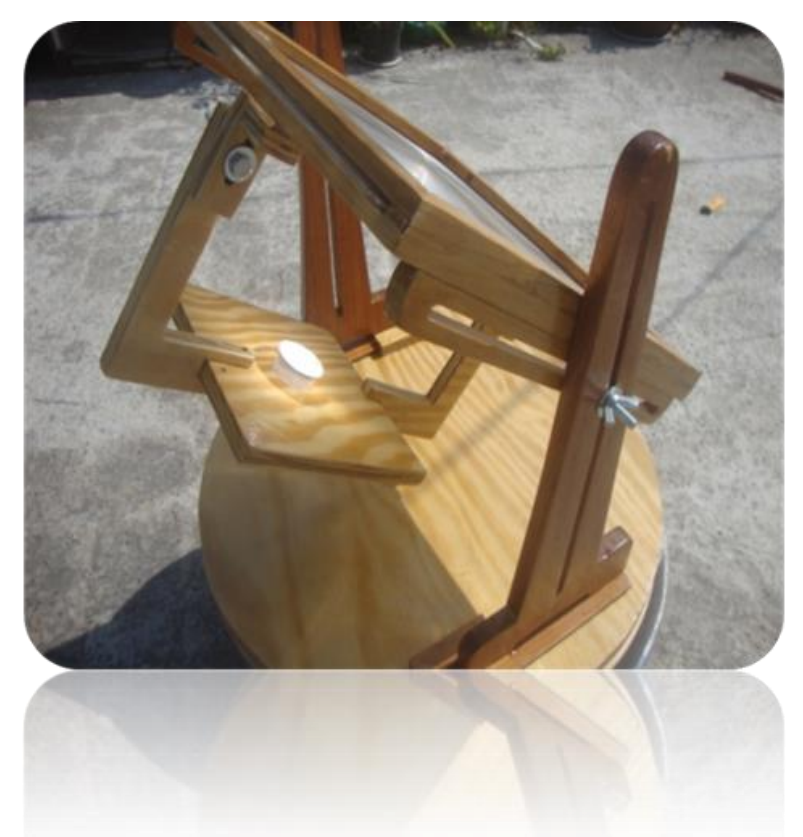

Fig. 12. Prototype of a Fresnel lens-type solar concentrator built at the Facultad de Ingeniería, UNAM; it can be observed the area where the optical focal point is located, which is where the surface treatments can be carried out for the materials.

An evidence of a resultant surface treatment achieved with these concentration systems can be observed in Fig. 13, in which a side view of a piece of steel heated by CSE and later quenching in water is observed. The image clearly shows the treated surface region [14].

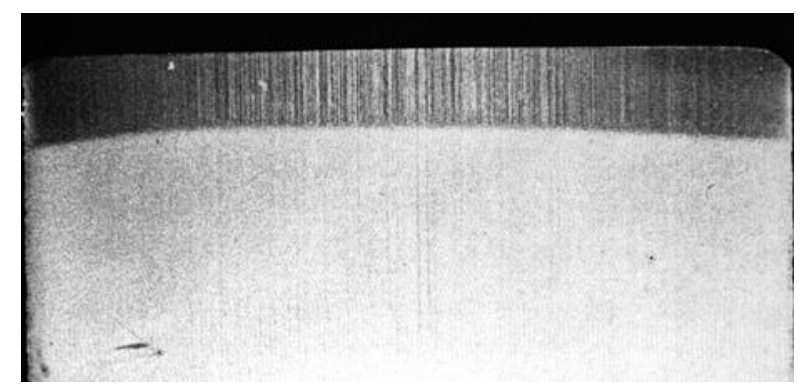

Fig. 13. Side view of a piece of hardened steel after heated by ESC using a Fresnel lens and subsequent cooling in water.

Fig. 14 shows a graph of the hardness of the CSE hardened piece shown in Fig. 13. The increase in hardness that is achieved in the superficially hardened zone is evident. On the surface, maximum hardness in the order of
700 units (Vickers) is achieved, while in the inner zone the values are around 200 units. It is interesting to highlight in this topic, the fundamental contribution of optics to achieve adequate concentration and the fact that the solar energy used is only a small part of the one that reaches our planet. The environmental benefits that come with it, and the processes that have been achieved with it in shorter times than conventional ones, make this new field of science very attractive [14].

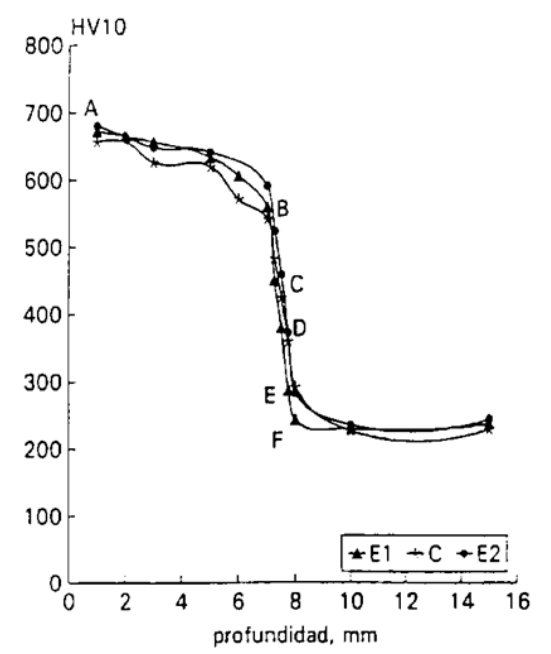

Fig. 14. Hardness graphs (Vickers microhardness) depending on the depth of the treated area [14].

\section{Coatings ObTained By Physical VAPOR DEPOSITION (PVD)}

One more possibility is to obtain coatings, most of them of high hardness for industrial purposes -especially in the field of mechanical tooling or application in the electronics industry- that could be obtained under appropriate experimental conditions (that is the main challenge of these technologies). A successful physical vapor deposition (PVD) process occurs when gaseous substance (vapor) goes to the solid phase (without going through the liquid) and gets deposited on a metallic substrate. The indicated state change (deposition) is illustrated in Fig. 15.

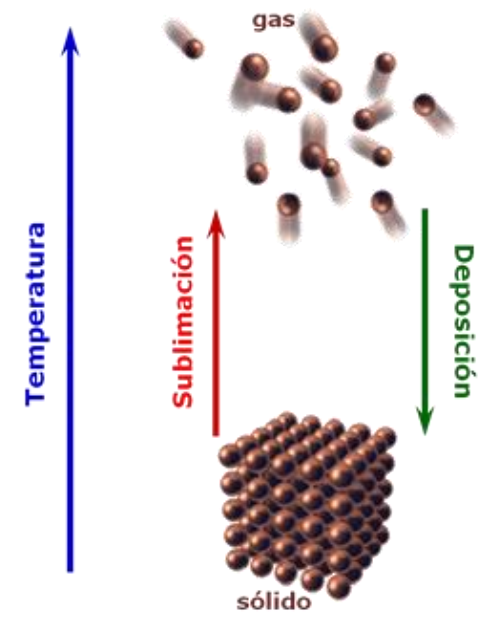

Fig. 15. Diagram with the different changes of state that can occur between solid and gas, depending on the temperature. As it can be observed the passage of gas to solid without going through the liquid is the deposition ${ }^{6}$

${ }^{6}$ Source: http://corinto.pucp.edu.pe/quimicageneral/contenido/56cambios-de-estado-diagramas-de-calentamiento-diagramas-de-fase.html 
Deposicion fisica del vapor PVD
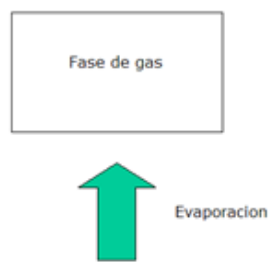

\section{Fase condensada
(liquida o solida)}

Figure 16.- Diagram of

cycle that, in general terms, that is carried out to obtain a coating by means of physical vapor deposition from the gaseous phase (vapor) ${ }^{7}$

Then, Fig. 16 also illustrates the general idea for obtaining this type of coatings. The material that will serve as a coating begins with its change of state from solid or liquid to gas using different technologies (evaporation with different forms of energy, sputtering, etc.); in this part of the process, the phenomena of evaporation is also described by Newton law for heat convection (eq. (2)), but with little difference due to boiling. The equation for Newton law for heat convection in this case will state [26]:

$$
\vec{q}=h\left(T_{S}-T_{\text {sat }}\right)
$$

In which the term (T_S-T_sat) is denominated "temperature excess", and it is the difference between the surface temperature of the walls containing the liquid T_S, and the saturation temperature of the liquid $T_{-}$sat at the given pressure. Again, the proportional constant $h$ is obtained experimentally, or considering theoretically relations with the phenomena. After boiling, the vapor is transported and finally its transformation from gas to solid over the surface to be treated in order to achieve the planned coating. Usually specific pressures and temperatures are used (particular thermodynamic conditions) for the different coatings, also the processes are carried out in a special reactor in which it is possible to achieve a very detailed and carefully control the process. Industrial coatings for mechanical use are commonly of a few micrometers and thus can double, triple and even more, the life of the tooling to which they are applied [18],[19].

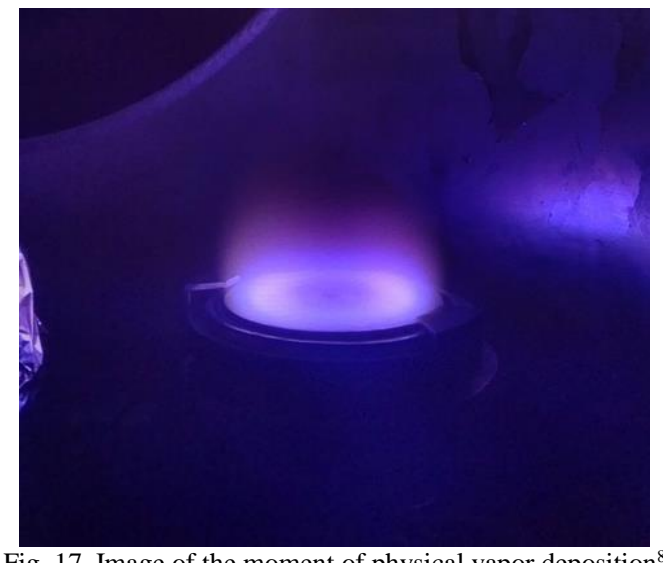

Fig. 17. Image of the moment of physical vapor deposition ${ }^{8}$

\footnotetext{
${ }^{7} \mathrm{http} / /$ www.galileog.com/ciencia/fisica/molecular/knudsen.htm

${ }^{8} \mathrm{https}: / /$ en.wikipedia.org/wiki/Sputter_deposition\#/media/File:Magnetro n_sputtering_source
}

Fig. 17 presents a photograph of a physical vapor deposition system (PVD), with a typical hue coming from the formation of plasma. An additional advantage of these processes is the environmentally friendly characteristic and a disadvantage is that it requires a large investment.

Fig. 18 represents a sample of tools that undergo this type of process.

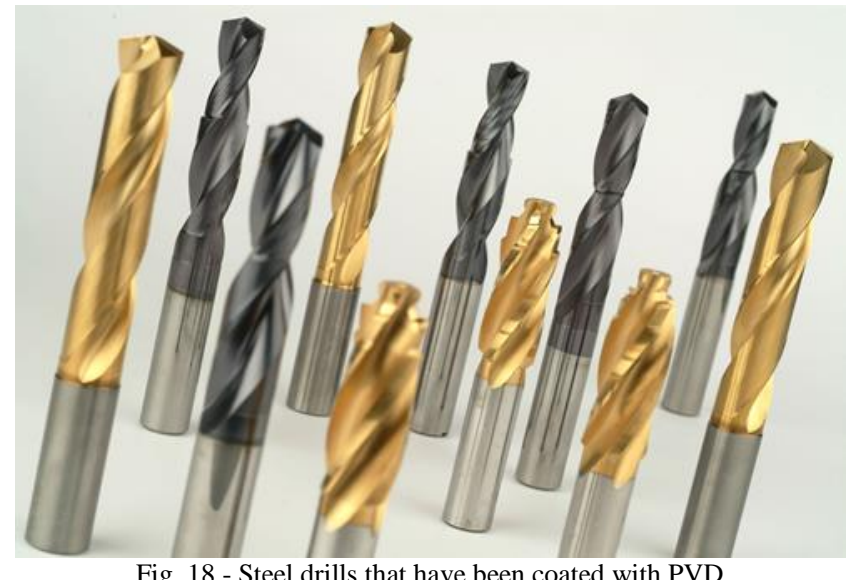

\section{CONCLUSION}

1. The contributions of Physics to the processes of surface treatment of materials, have been relevant since the beginning and have contributed in a decisive way to its development.

2. Physics and its principles have undoubtedly impacted and promoted improvements to the various surface technologies that are applied in the industrial context, and those that are researched and developed in laboratories of universities and research centers.

3. This work particularly highlights the contributions of optics, phenomena associated with heat transfer and electricity, which can become a way or a medium to take advantage of a resource, to heat the surfaces of pieces.

4. There is a unique opportunity to improve the process in each technology, that is to first understand each of the physics principles involved and then to develop in that particular part on the complete process in order to enhance the complete performance.

5. The main objective of this pair of works is to show students how the principles they have studied in their General Physics classes are applied in industrial application equipment and have been of essential importance in the development of the processes that allow to improve the performance of a material, by means of the surface treatments.

\section{ACKNOWLEDGMENT}

Research carried out thanks to the PAPITT Program IT101318 "Desarrollo de Tecnologías de Superficie para la Optimización de Componentes y Sistemas" and PAPIME Program PE100218 "Programa para la Actualización y Mejora de la Enseñanza y el Aprendizaje de Temas de Materiales, Manufactura e Ingeniería de Superficies a estudiantes de Ingeniería" of the DGAPA of the UNAM. 


\section{REFERENCES}

[1] Ruglic T. Flame Hardening of Steels. ASM Handbook Volume 4, Heat Treating (ASM International). 1990. p. 268-285

[2] Raja B. Flame Hardening Metallurgical Process for Surface Hardening of Steel Components. SteelWorld. May 2009. p.56-60.

[3] Lee. M., Kimb, G., Kimc K., Hongd S. Kime W., Cracks in Flame Hardening Surface Treatment of $12 \mathrm{Cr}$ blade steel. Solid State Phenomena Vol. 118 (2006) pp 191-196.

[4] Jeyaraj. S., Arulshri K, Harshavardhan K, Sivasakthivel P. Optimization of Flame Hardening Process Parameters Using LS Orthogonal Array of Taguchi Approach. International Journal of Engineering and Applied Sciences (IJEAS) ISSN: 2394-3661, Volume-2, Issue-3, March 2015.

[5] Bello L.,Mazzola G. Massimo M. La correcta selección de un equipo para el templado por inducción. 2009.

[6] Rudnev V. Induction Hardening of Gears and Critical Components. Part II. Gear Technology. Nov/Dec 2008. p.47-53.

[7] Doyon G., Rudnev V., Maher J. Low-distortion, high-quality induction hardening of crankshafts and camshafts. Advanced Materials and Process. Sept 2013. p. 59-61.

[8] Zhichao L., Ferguson. B. Nemkov V. Goldstein R. Jackowski J., Fett F. Modeling distortion and residual stresses of an induction hardened truck axle. Advanced Materials and Process. Sept 2013. p. 62-64

[9] Steen W. Mazumder J. Basic Laser Optics Capítulo de Laser Material Processing. Springer 2010. p. 79-129. ISBN 978-1-84996- 061-8

[10] Sheen M. Basic of Laser and Laser Optics. Chapter 2 of Laser Processing of Materials. Fundamentals, Applications and Developments. 2010. Springer. p. 5-20. ISBN 978-3-642-13280-3

[11] Grum J. Šturm R. Microstructure variations in the laser surface remelted layer of nodular iron. Int. J. Microstructure and Materials Properties, Vol. 1, No. 1, 2005. p. 11-23

[12] Purushothaman B., Gengusamynaidu B., Karupuudaiyar B. Experimental studies on the microstructure and hardness of laser transformation hardening of low alloy steel. Transactions of the Canadian Society for Mechanical Engineering, Vol. 36, No. 3, 2012. p. 241-258.

[13] Dobrzañski L. Jonda E, Klimpel A. Laser surface treatment of the hot work tool steel alloyed with TaC and VC carbide powders. Archives of Materials Science and Engineering. Vol 37 Issue 1, May 2009, p.53-60.

[14] Rodriguez G., Damborenea J. Vázquez A. Surface hardening of steel in a solar furnace. Surface and Coatings Technology 92 (I997) 165 170 .
[15] Xiea W., Daia,Y. Wanga R., Sumathyb K. Concentrated solar energy applications using Fresnel lenses: A review. Renewable and Sustainable Energy Reviews 15 (2011) 2588- 2606

[16] Martinez D., Cañadas I. Mallol G., Tellez F., Rodríguez J. A case study of the feasibility of using solar concentrating technologies for manufacturing ceramics. Journal of Cleaner Production 87 (2015) p. 977-991

[17] Herranz G., Romero A. Castro V. Rodríguez G. Development of high speed steel sintered using concentrated solar energy. Journal of Materials Processing Technology 213 (2013) 2065- 2073.

[18] Mubarak A., Hamzah E., Toff M. Review of Physical Vapor Deposition (PVD) Techniques for Hard Coating. Jurnal Mekanikal. Dec. 2005. No. 20. 42-51.

[19] Gómez M. Caracterización de las Propiedades Tribológicas de Recubrimientos Duros. Tesis Doctorado. Universidad de Barcelona. 2005. España.

[20] Sierra C., Vázquez A.J. NiAl coatings on carbon steel by selfpropagating high-temperature synthesis assisted with concentrated solar energy: mass influence on adherence and porosity. Solar Energy Materials \& Solar Cells, 86 (2005), 33-42.

[21] Fishman R.S. Thomas Harriot and the Sine Law of Refraction. Arch Ophthalmol Vol.118 March 2000, 406 - 409. Doi: 10.1001/archopht.118.3.405

[22] Mondal A.K., Kumar S., Blawert C., Dahotre N.B. Effect of laser surface treatment on corrosion and wear resistance of ACM720 Mg alloy. Surface \& Coatings Technology, 202 (2008), 3187-3198.

[23] Incropera F.P., DeWitt D.P. Fundamentos de Transferencia de Calor. Chapter 1. Prentice Hall, 1999.

[24] José Manuel Villalba, Luciana Ferreira, Enrique Arribas, Alberto Nájera, Augusto Beléndez. Estudio experimental de la inducción electromagnética entre dosbobinas: Dependencia con la corriente eléctrica. Revista Brasileira de Ensino de Física, v. 37, n. 1, 1313 (2015). Doi: 10.1590/S1806-11173711697

[25] Julio-Betancourt G.A., Hooton R.D. Study of the Joule effect on rapid chloride permeability values and evaluation of related electrical properties of concretes. Cement and Concrete Research, 34 (2004), 1007-1015. Doi: 10.1016/j.cemconres.2003.11.012

[26] Incropera F.P., DeWitt D.P. Fundamentos de Transferencia de Calor. Chapter 10. Prentice Hall, 1999. 